\title{
Tegument proteins of Kaposi's sarcoma-associated herpesvirus and related gamma-herpesviruses
}

\author{
Narayanan Sathish ${ }^{1}$, Xin Wang ${ }^{2}$ and Yan Yuan ${ }^{2}$ \\ ${ }^{1}$ Department of Biological Sciences, Indian Institute of Science Education and Research Bhopal, Bhopal, Madhya Pradesh, India \\ ${ }^{2}$ Department of Microbiology, School of Dental Medicine, University of Pennsylvania, Philadelphia, PA, USA
}

\section{Edited by:}

Keiji Ueda, Osaka University Graduate

School of Medicine, Japan

\section{Reviewed by:}

Paul Dalling Ling, Baylor College of Medicine, USA

Jeremy Phillip Kamil, Louisiana State University Health Sciences Center,

USA

\section{*Correspondence:}

Narayanan Sathish, Department of Biological Sciences, Indian Institute of Science Education and Research Bhopal, ITI (Gas Rahat) Building, Govindpura, Bhopal 462023, Madhya Pradesh, India.

e-mail: sathishn@iiserb.ac.in
A herpesvirus virion is composed of a viral genomic DNA-containing capsid surrounded by a viral envelope with glycoprotein spikes on its surface. Located between the capsid and the outer viral envelope is the virion tegument layer. Though the majority of the virion proteins are located in the tegument, this layer is less studied and was thought to be an amorphous structure. Over the last decade, a number of studies have indicated the presence of organized tegument structures across the spectrum of herpesviruses, implicating tegument components in critical steps governing the viral life cycle. In the case of Kaposi's sarcoma-associated herpesvirus (KSHV), the etiological agent of Kaposi's sarcoma, several functions exerted by tegument proteins at different stages of the viral life cycle, inclusive of primary de novo infection and virion assembly, have been identified over the last several years. In this review, KSHV tegument components are cataloged and the occurrence of organized tegument structures in $\mathrm{KSHV}$, built through interactions amongst the different virion proteins, is discussed in depth. The significant functional roles of the KSHV tegument proteins at different stages of the viral life cycle are elaborated under separate headings. Definitive functional roles exerted by tegument proteins of related gamma-herpesviruses are also discussed. Since tegument proteins play key roles during viral assembly, viral entry, and represent an important interface for virus-host interactions, further research in this area should provide detailed insights into the functional capacity of the KSHV tegument, resulting in a better understanding of the viral life cycle.

Keywords: Kaposi's sarcoma-associated herpesvirus, human herpesvirus type 8, tegument, virion, protein interaction, virion assembly
Kaposi's sarcoma-associated herpesvirus (KSHV) is the etiological agent of Kaposi's sarcoma (KS). Based on phylogenetic analysis, $\mathrm{KSHV}$ is placed in the human herpesviridae family and gamma herpesvirinae sub-family along with other closely related gammaherpesviruses such as Epstein-Barr virus (EBV; Chang et al., 1994; Moore et al., 1996; Russo et al., 1996). KSHV being the last addition to the human herpesvirus group is thus also designated as the human herpesvirus-8 (HHV-8; Moore et al., 1996; Russo et al., 1996). KSHV was first identified in 1994 from a KS lesion (Chang et al., 1994) and thereafter has been found to be unequivocally associated with KS (Chang et al., 1994; Dupin et al., 1995; Moore and Chang, 1995; Schalling et al., 1995; Chuck et al., 1996). Prior to the AIDS epidemic, KS was a rare disease occurring predominantly in elderly men across the Mediterranean and Middle East regions (Dupin et al., 1995). KS is now recognized as a leading cause of death in AIDS patients (Moore and Chang, 1995; Antman and Chang, 2000; Ganem, 2010). The AIDS-associated KS (AIDS-KS) manifests frequently on the skin with high propensity to spread to multiple organs such as lungs and the gastrointestinal tract (Dezube, 1996; Ganem, 2010). AIDS-KS is the most common oral malignancy in HIV-infected individuals contributing to about $70-90 \%$ of all AIDS-associated oral tumors (Antman and Chang, 2000). In addition to KS, KSHV is also implicated in two other lymphoproliferative disorders, namely the primary effusion lymphoma (PEL; Cesarman et al., 1995a) and the plasma cell variant of multicentric Castleman's disease (MCD; Soulier et al., 1995).

Similar to other herpesviruses, KSHV exhibits two alternative phases in its life cycle, the lytic and latent. Primary infection of a host cell begins with the entry of KSHV viral particles into the cell which get transported to the nucleus (Akula et al., 2001; Wang et al., 2001; Chandran, 2010). The viral genomic DNA is released into the nucleus and establishes viral latency by default (Cesarman et al., 1995b; Ballestas et al., 1999). In latently infected cells, there is expression of only a limited number of viral (latent) genes and no infectious virions are produced (Zhong et al., 1996; Sarid et al., 1998). The latent viral genome undergoes periodic lytic reactivation followed by a temporally regulated cascade of viral gene expression (Renne et al., 1996; Miller et al., 1997; Sun et al., 1999). The newly expressed viral proteins assemble to form infectious mature virions which egress out of the cell and initiate primary infection of uninfected cells (reviewed in Ganem, 2007).

Unlike other herpesviruses where the latent life cycle is usually responsible for the disease potential, in KSHV, the lytic cycle is also responsible, contributing to tumorigenesis. The most compelling evidence for this notion is the observation that treatment of KS patients or AIDS patients at risk for KS with anti-herpesviral drugs, such as Foscarnet and ganciclovir that block lytic but not 
latent $\mathrm{KSHV}$ replication, resulted in regression of KS lesions with a decrease in the incidence of KS development (Morfeldt and Torssander, 1994; Martin et al., 1999). Furthermore, the productive replication cycle directly contributes to viral tumorigenesis by spreading viruses to target cells and providing paracrine regulation for KS development (Cesarman et al., 2000). An early study by Grundhoff and Ganem (2004) suggests a role of lytic replication in sustaining the population of latently infected cells that otherwise would be quickly lost by segregation of latent viral episomes as spindle cells divide. Thus, KSHV lytic replication and constant primary infection to fresh cells are crucial for viral tumorigenicity. Given the importance of the KSHV lytic cycle in both viral propagation and tumorigenesis, a thorough understanding of viral lytic replication processes including virion assembly and egress becomes vital.

\section{KSHV VIRION STRUCTURE AND PROTEINS}

A typical herpesviral particle (or virion) consists of the following morphologically distinct components: (i) a core which contains a linear double stranded viral DNA enclosed within an icosahedral capsid, (ii) an outer envelope with viral glycoproteins appearing as spikes on the surface, and (iii) an electron-dense material defined as the tegument, located between the capsid and envelope (Pellet and Roizman, 2007). During the lytic cycle, almost the entire set of KSHV viral genes are expressed. Approximately one-third of these viral genes encode virion proteins that assemble into infectious virions. These virion proteins are thought to contain the functional information required for both de novo primary infection and for the KSHV virion assembly and egress. Employing proteomic approaches, two independent studies identified nearly thirty KSHV virion proteins from purified KSHV virions (Bechtel et al., 2005; Zhu et al., 2005).

Among these virion proteins, five are characterized as capsid proteins (Nealon et al., 2001). Specific interactions amongst these capsid proteins mediate capsid assembly processes (Sathish and Yuan, 2010). Seven virion proteins are specified as viral glycoproteins, mediating entry of KSHV into host cells through interactions with the host cell surface receptors (Baghian et al., 2000; Akula et al., 2001; Wang et al., 2001; Naranatt et al., 2002; Koyano et al., 2003; Chandran, 2010). Although the viral capsid and the envelope are well-characterized, the KSHV tegument remains largely undefined. The first step toward defining the KSHV tegument was an identification of its component proteins. The majority of earlier identified KSHV virion proteins were characterized as tegument components, on the basis of specific biochemical criteria. These criteria included (i) resistance to trypsin digestion in the absence of detergent and (ii) susceptibility to trypsin digestion following treatment with outer viral envelope dissolving detergents (Bechtel et al., 2005; Zhu et al., 2005). Based on these criteria, proteins encoded by ORFs $21,33,45,64$, and 50 (replication transcription activator/Rta) are identified as components of the KSHV tegument (Bechtel et al., 2005; Zhu et al., 2005). In addition, proteins encoded by ORFs $6,7,11,52,63$, and 75, which belong to neither the capsid nor the viral envelope, are also considered putative tegument proteins (Bechtel et al., 2005; Zhu et al., 2005). Among these, (i) ORFs 11,52, and 75 are identified as tegument components in closely related gamma-herpesviruses such as murine herpesvirus-68 (MHV-68) and murid herpesvirus 4
(MHV-4; Bortz et al., 2003, 2007; Gaspar et al., 2008). On the basis of considerable sequence similarity, the KSHV homologs of these ORFs are also considered tegument components (Bechtel et al., 2005; Zhu et al., 2005); (ii) the analog of ORF63 in HSV-1 is a well-characterized tegument protein and is predicted to encode for a tegument protein in KSHV as well (Russo et al., 1996; Zhu et al., 2005); (iii) ORFs 6 and 7 are yet to be characterized (May et al., 2005a,b). ORF19 and ORF67 are also predicted to encode for tegument proteins, based on their sequence homology to tegument proteins of other well-characterized herpesviruses and await further characterization (Russo et al., 1996). Taken together, proteins encoded by ORFs $11,21,33,45,50,52,63,64$, and 75 are currently considered as KSHV tegument proteins with several more to be characterized.

Though the tegument was earlier considered an amorphous layer of proteins, recent studies indicate the occurrence of ordered tegument structures built through specific protein-protein interactions in HSV-1 (Zhou et al., 1999; Vittone et al., 2005), human cytomegalovirus (HCMV; Chen et al., 1999; Phillips and Bresnahan, 2011), and MHV-68 (Dai et al., 2008). Figure 1 illustrates a $3 \mathrm{D}$ structure of MHV-68 virion reconstructed by cryoET, which demonstrates a two-layered organization of the tegument. The inner tegument layer (green in Figure 1B) remains tethered to the capsid by directly interacting with it. The outer tegument (violet in Figure 1B) occupies the space between the inner layer and the envelope, and is much more loosely organized, as it conforms to the irregular shape of the viral envelope.

Further details regarding the tegument architecture were obtained through a systematic investigation of the KSHV tegument protein interactions (Figure 2). A total of 37 binary protein interactions were detected between the KSHV tegument proteins and the different virion proteins (inner capsid proteins/tegument proteins/outer envelope glycoproteins; Rozen et al., 2008). This observation pointed to the occurrence of organized tegument structures in KSHV also. A significant proportion of the above interactions are mediated by the tegument proteins encoded by ORFs 21, 33, 45, 52, 63, 64, and 75 (Rozen et al., 2008).

\section{FUNCTIONAL ROLES OF KSHV TEGUMENT PROTEINS IN VIRAL ASSEMBLY PROCESSES}

Herpesviral assembly is a multi-stage process consisting of the following events: (i) incorporation of the newly replicated DNA into the pre-formed capsid within the nucleus generating the viral nucleocapsid; (ii) exit of the nucleocapsid from the nucleus into the cytoplasm through a sequence of coordinated steps such as acquisition of a primary envelope (from the nuclear membrane) by the nucleocapsid and its subsequent loss; (iii) acquisition of tegument proteins by the nucleocapsid in the cytoplasm and transportation of tegumented capsids to sites of final envelopment, the Golgi-derived vesicles; (iv) final envelopment including acquisition of other tegument and envelope glycoproteins by budding into the vesicles; and (v) egress of mature virions from the infected cell following fusion of the vesicle membrane with the cell plasma membrane (reviewed in Mettenleiter, 2002; Mettenleiter et al., 2009). Although the above framework for herpesvirus assembly and egress may be common to all herpesviruses, the detailed steps and the mechanisms underlying these processes have been less studied in gamma-herpesviruses including KSHV. 


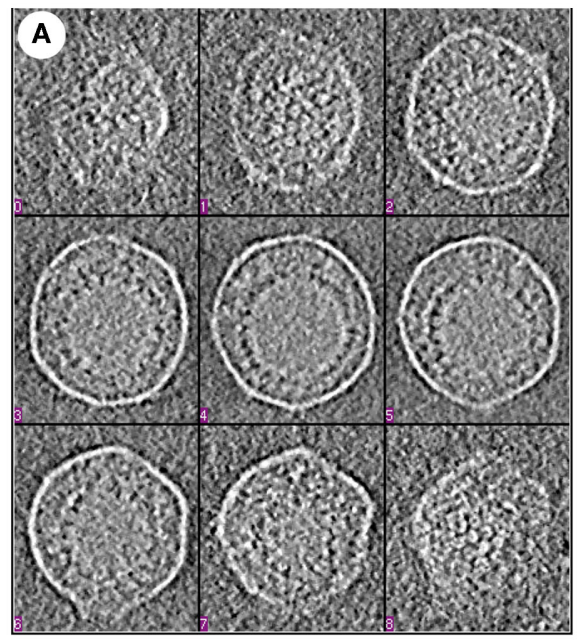

FIGURE 1 | 3D structure of an MHV-68 virion reconstructed by cryo-electron tomography. (A) Tomogram slices from a representative HMV-68 virion. (B) Shaded surface representation of central slabs of the virion segmented from the tomogram shown in (A). Color coding: red, internal density in capsid; yellow, capsid shell; green, inner layer tegument;

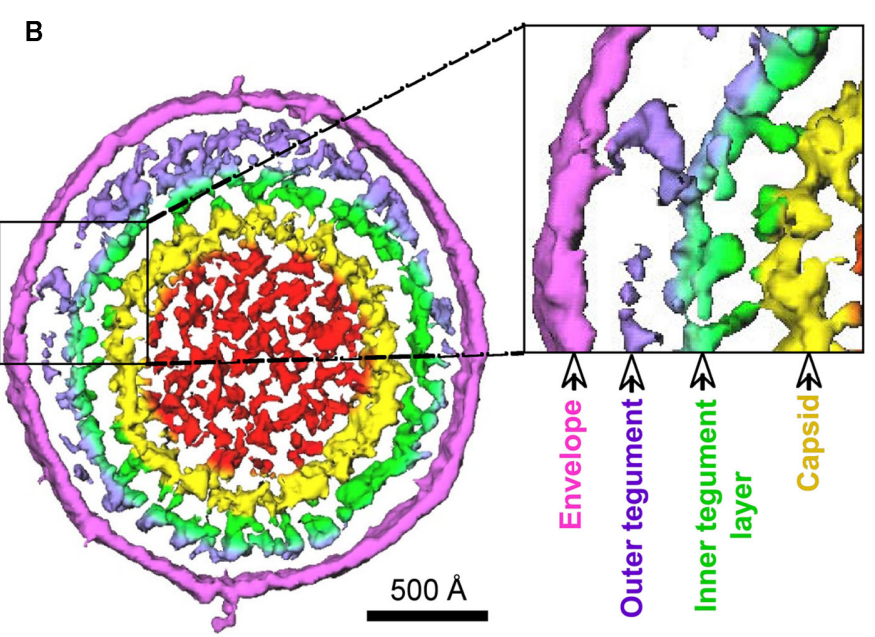

violet, outer layer tegument; magenta, viral envelope. Two layers of tegument are shown: an inner tegument layer tethered to the underlying capsid and an outer tegument layer conforming to the overlying envelope. This figure is adapted from Dai et al. (2008), courtesy of Z. Hong Zhou at UCLA, with permission from Elsevier Press, Oxford, UK.

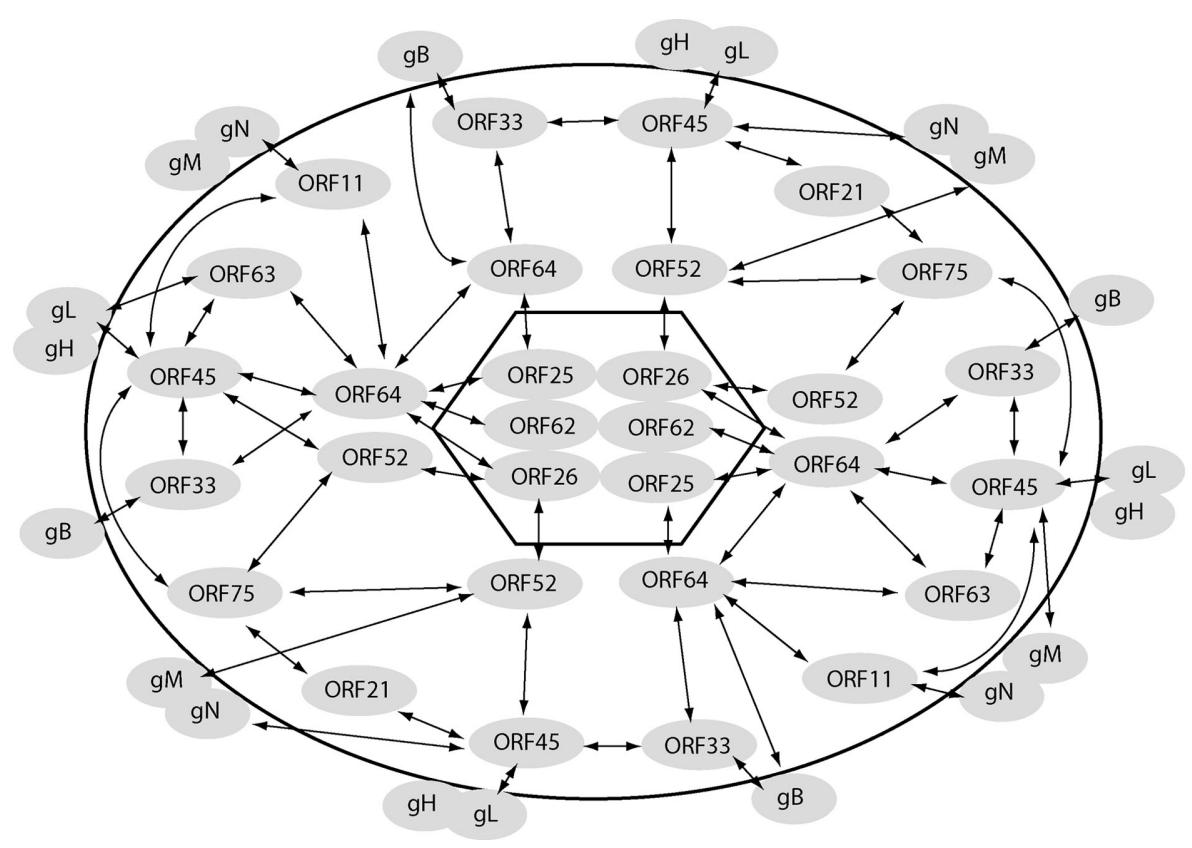

FIGURE 2 | Interactome map of KSHV virion proteins. Interactions amongst the virion proteins, capsid (inside the hexagon), tegument (outside the hexagon but within the oval), and envelope (outside oval) are indicated with arrows. The interaction pattern of the ORF64-ORF52-ORF33-ORF45 network with multiple virion proteins is evident from the figure.
Dynamic and intricate interactions mediated by the tegument proteins amongst themselves as well as with the inner capsid and the outer envelope proteins impacts both tegumentation and envelopment in related herpesviruses like HSV and HCMV thus influencing viral assembly processes (Mettenleiter, 2002; Mettenleiter et al., 2009). Given the homology amongst tegument proteins of herpesviruses, it is reasonable to assume that tegument proteins in KSHV could also influence virion assembly pathways. As a first step toward bridging the existing gap, interactions of the KSHV tegument proteins with the different virion proteins (capsid/tegument/envelope) have been systematically investigated (Rozen et al., 2008). This has led to a revelation of a virion-wide 
protein interaction network (Figure 2). This network is expected to serve as a road map to gain insights into the less studied but critical KSHV tegumentation and viral assembly processes. Here we attempt to summarize the knowledge accumulated over the recent years regarding roles of KSHV tegument proteins in virion assembly and egress.

\section{ORF64}

This ORF encodes for a $290-\mathrm{kDa}$ tegument protein and is the largest protein encoded by the KSHV genome. Homologues of ORF64 exist across the three herpesvirus sub-families (Zhu et al., 2005). The earlier established KSHV protein interaction map indicated a diverse interaction potential of ORF64. This protein was found to interact with three viral capsid proteins, namely ORFs 25 (major capsid protein/MCP), 26 (TRI-2), and 62 (TRI-1; Rozen et al., 2008), suggesting an attachment of ORF64 to the icosahedral capsid structure (Figure 2). This is likely to be true as the HSV-1 analog, VP1/2 encoded by UL36, is also involved in a tight interaction with the viral capsid (McNabb and Courtney, 1992; Newcomb and Brown, 2010). A three-dimensional image reconstructed from a cryo-electron microscopic study of HSV-1 particles revealed interactions of the ORF64 homolog of HSV-1 (VP1/2) with MCP, TRI-2, and TRI-1 (Zhou et al., 1999). There is no doubt that the association of ORF64 with three capsid proteins is conserved across the herpesvirus family.

KSHV ORF64 was also found to interact with several tegument proteins including ORFs $11,21,33,45,63,75$ and with itself (Rozen et al., 2008). The interactions of ORF64 with a plethora of tegument proteins has led to a hypothesis that ORF64 functions as a major hub or a scaffold protein, recruiting other tegument proteins during KSHV virion tegumentation (Rozen et al., 2008). ORF64 also interacted with several envelope glycoproteins (Rozen et al., 2008). This finding justifies a rather peculiar behavior of ORF64 wherein its degradation was noticed subsequent to treatment of intact virion particles with trypsin, despite the absence of envelope dissolving detergent, suggesting its association with the viral envelope as well (Zhu et al., 2005). The ability of ORF64 to interact with KSHV glycoproteins is consistent with a role of this protein in positioning the DNA-filled tegumented capsid at the trans-Golgi apparatus through association with envelope glycoproteins, promoting secondary envelopment processes. Delineating the interaction dynamics of KSHV ORF64 with the different virion components is needed to identify the step/s in which these interactions occur in the viral assembly pathways.

\section{ORF45}

This ORF encodes a protein of 407 amino acids (Zhu and Yuan, 2003; Zhu et al., 2005), homologues of which are present only in gamma-herpesviruses. An important functional role of ORF45 in KSHV assembly pathways was suggested in a study employing an ORF45-null recombinant KSHV (Zhu et al., 2006). A noticeably lowered yield of progeny virions was obtained from ORF45-null recombinant mutant virus reconstituted cells as compared to that obtained from cells reconstituted with the wild-type virus though viral gene expression and viral DNA replication remained unaffected in the absence of ORF45 (Zhu et al., 2006). A specific role of ORF45 in KSHV virion assembly was revealed by the finding that
ORF45 interacts with the microtubule (MT) associated kinesin-2 motor protein, KIF3A, and mediates the docking of entire viral capsid-tegument complex on to the cargo-binding domain of KIF3A (Sathish et al., 2009). KIF3A is involved in transportation of cargo along the MTs from the nucleus toward the cell periphery (Yamazaki et al., 1995; Hirokawa, 2000). Inhibition of KIF3A-ORF45 interaction with a headless dominant negative (DN) mutant of KIF3A or by an shRNA-mediated silencing of endogenous KIF3A expression decreased KSHV particle release noticeably. These approaches, did not impact HSV-1 virion release, demonstrating the specificity of KIF3A in transport of KSHV particles. The above observations led to a proposed model (Figure 3) on the role of ORF45 in KSHV assembly and egress, wherein (i) subsequent to nuclear egress, KSHV capsids acquire tegument proteins such as ORFs 64, 63, and 45 in the cytoplasm, (ii) ORF45 recruits KIF3A and mediates loading of the viral particles onto KIF3A, and (iii) the viral particles are transported along the MTs from the peri-nuclear region to the cell periphery or transGolgi network (TGN) membrane for final envelopment and egress (Sathish et al., 2009). The KSHV envelope glycoproteins were not transported along with the KSHV tegument-capsid complexes, indicating that as newly assembled viral tegumented capsids are transported by kinesin-2 to sites of further envelopment, viral glycoproteins travel separately.

\section{ORF52}

This ORF encodes a small protein of $21 \mathrm{kDa}$, conserved across the gamma-herpesviruses with homologs in both the closely related MHV-68 and EBV (Bortz et al., 2003; Zhu et al., 2005). ORF52 has been characterized as a tegument protein in MHV-68 on the basis of its presence in the detergent-resistant pellet fraction subsequent to detergent treatment and centrifugation of virions and its absence in the capsid pellet fraction subsequent to treatment of virions with non-ionic detergent by high salt extraction and centrifugation (Bortz et al., 2007). MHV-68 ORF52 shares a 28\% identity with the KSHV homolog, thus serving as a useful model to assess the functional roles of the less studied KSHV ORF52 (Zhu et al., 2005; Bortz et al., 2007).

An ORF52-null recombinant MHV-68 exhibited no apparent defects in viral DNA replication, viral lytic gene expression, and capsid assembly processes. A normal nuclear accumulation of viral capsid structures was noticed by TEM-based approaches (Bortz et al., 2007). Though partially tegumented nucleocapsids could be seen juxtaposed to the trans-Golgi vesicular membranous compartments, enveloped virions were not noticed within these membranous vesicles. Analysis of these partially tegumented capsids revealed the presence of capsid proteins and tegument proteins such as ORF64 and ORF67 but the absence of other tegument proteins such as ORF45 and ORF42 (Bortz et al., 2007). Structural studies performed on MHV-68 ORF52 have indicated the existence of an $\mathrm{N}$-terminal $\alpha$-helical domain which interacts with the other tegument protein partners (Benach et al., 2007). Failure of an ORF52 mutant (lacking the N-terminal $\alpha$-helix) in compensating defective virion production seen with a MHV-68 ORF52-null mutant virus clearly demonstrated the necessity of the interactions between ORF52 and other tegument proteins (Benach et al., 2007). All the above observations suggested a vital role of ORF52 

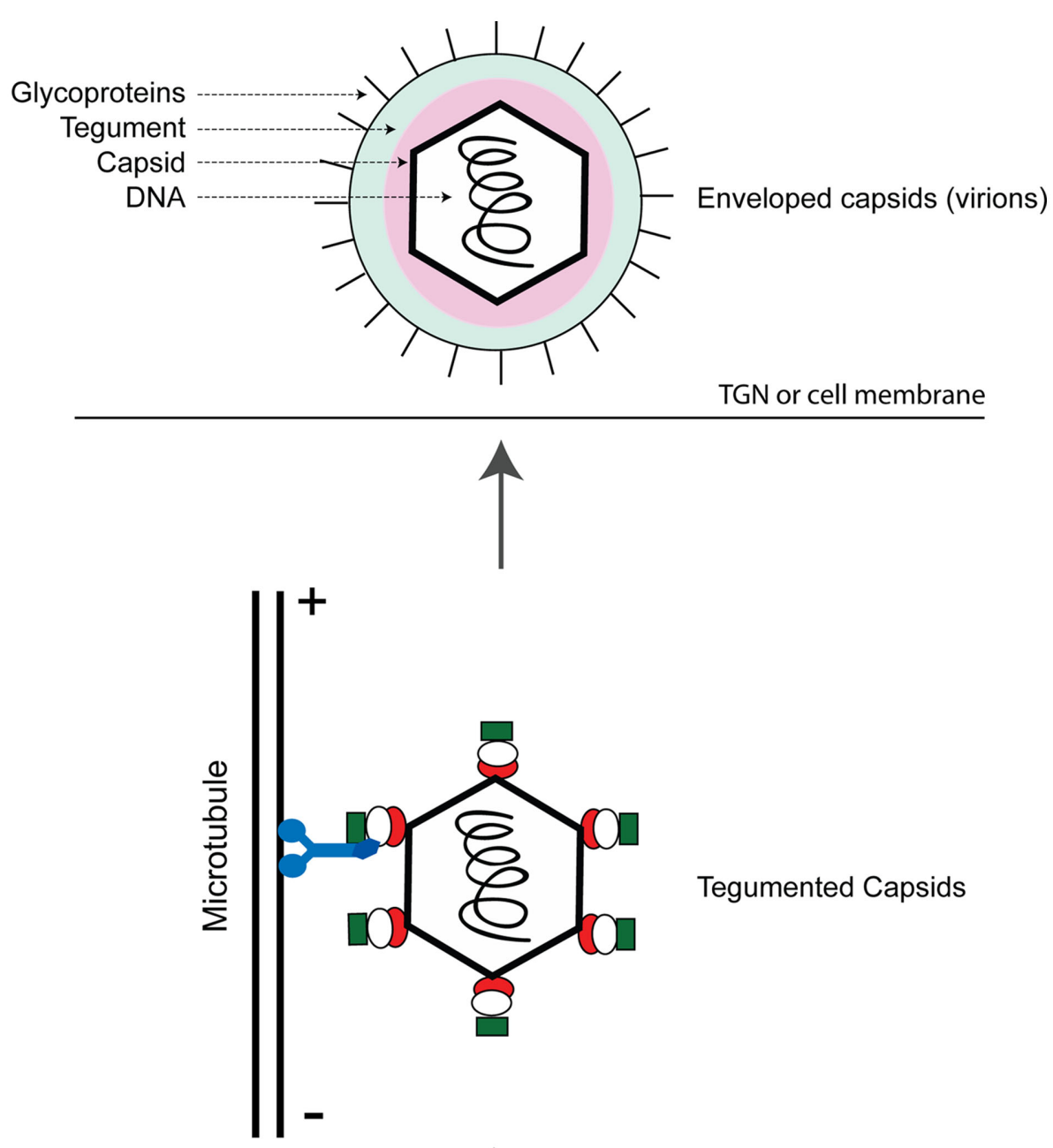

Nuclear membrane

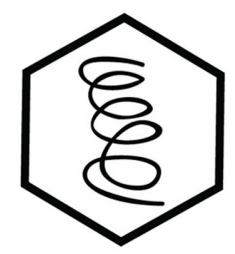

\section{Nucleocapsids}

ORF45

Other tegument proteins (ORFs 64 and 33)

FIGURE 3 | Role of ORF45 in mediating transportation of assembled KSHV capsid-tegument complexes on microtubules toward sites of maturation/envelopment and egress. Newly synthesized

nucleocapsids exit out of the nuclear compartment wherein they acquire the tegument proteins including ORFs 33,45 , and 64 . ORF45 on the viral particles binds to KIF3A, docking the entire viral capsid-tegument complexes onto it. The complexes are then transported along microtubules either to trans-Golgi network (TGN) or the cell membrane for further envelopment and viral egress. This figure is adapted from Sathish et al. (2009). in MHV-68 tegumentation during viral assembly. On the basis of considerable homology in ORF52 sequences between MHV-68 and $\mathrm{KSHV}$, it is tempting to speculate that similar structural and functional characteristics could be exhibited by KSHV ORF52 also. 


\section{ORF33}

This ORF encodes a tegument protein of 334 amino acids and homologs of this protein are present across all three herpesvirus sub-families (Jenner and Boshoff, 2002; Zhu et al., 2005; Guo et al., 2009). Though functional studies on ORF33 have not been undertaken in KSHV, such studies were performed in MHV-68. An ORF33-null recombinant MHV-68 has provided useful information on the functional role of this protein in virion assembly. This mutant virus did not exhibit any defects in viral DNA replication, viral gene expression and viral capsid assembly. However, a TEM-based analysis of thin sections obtained from ORF33-null MHV-68 virus carrying cells showed a defective release of nucleocapsids from the nucleus into the cytoplasm. Enveloped virions were not seen both within the cytoplasmic vesicles and in the extracellular space (Guo et al., 2009). These observations are consistent with the functional roles of ORF33 homologues in both HSV1 (UL16; Meckes and Wills, 2007) and HCMV (UL94; Liu et al., 2009) in directing partially tegumented particles to the trans-Golgi vesicles. Analysis of the intracytoplasmic partially tegumented particles of ORF33-null MHV-68 revealed the presence of capsid proteins and some tegument proteins including ORF64 and ORF52 though ORF45 was absent (Guo et al., 2009). These observations indicate a pivotal role of ORF33 in MHV-68 tegumentation and viral assembly. It would be worthwhile to investigate if KSHV ORF33 also exerts a similar function.

\section{PERSPECTIVES ON THE ROLES OF KSHV TEGUMENT PROTEINS IN VIRAL ASSEMBLY PATHWAYS}

The above studies indicate the critical roles exerted by tegument proteins of KSHV and other related gamma-herpesvirus in viral assembly processes. The earlier established KSHV virion protein interaction network indicates the functional potential of an ORF64-ORF52-ORF33-ORF45 network (Figure 2) in both tegumentation and secondary envelopment processes (Rozen et al., 2008) and hence would need to be further investigated. Since virion assembly and egress are dynamic processes, interactions among virion proteins could be transiently exerted at different stages in the viral life cycle (Meckes and Wills, 2007). These dynamic interactions could either be environment-dependent (such as $\mathrm{pH}$ regulated) or could occur as the viral particles travel through the assembly and egress pathway. Thus the focus of the virion assembly studies would also need to shift toward identifying the $\operatorname{step}(\mathrm{s})$ in the KSHV viral assembly pathway at which specific protein interactions come into play. Though much remains to be discovered, certain approaches as above could result in a better understanding of the functional roles of the tegument proteins in KSHV assembly.

\section{FUNCTIONAL ROLES OF KSHV TEGUMENT PROTEINS IN VIRAL ENTRY PATHWAYS}

Kaposi's sarcoma-associated herpesvirus infects a broad range of cell types in vitro resulting in viral latency. Establishment of KSHV latency requires the delivery of the viral genome into the host cell nucleus which is preceded by a well connected sequence of events. The first step involves the binding of KSHV virions, specifically the viral envelope glycoproteins (e.g., gB and gpK8.1A), to the ubiquitously expressed heparan sulfate (HS) cell surface receptor (Akula et al., 2001; Birkmann et al., 2001; Wang et al., 2001; Hahn et al., 2009), followed by temporal interactions with integrin molecules and other transmembrane proteins such as xCT (CD98) (Akula et al., 2002; Kaleeba and Berger, 2006; Veettil et al., 2008). Subsequent to the initial binding, the viral particles enter the infected cells within endocytic vesicles, releasing tegumented capsids into the cytoplasm by fusion of the viral envelope with the endocytic vesicles (Akula et al., 2003; Raghu et al., 2009; reviewed in Chandran, 2010).

Transportation of the tegumented capsids to the nucleus involves a complex interplay between cellular and viral components. Confocal microscopic images of KSHV infected cultured cells revealed a close association of incoming KSHV viral particles with MTs. Treatment of these cells with MT depolymerizing agents disrupted the association resulting in an inhibition in nuclear delivery of the viral DNA (Naranatt et al., 2005; Raghu et al., 2007, 2009). Dyneins are minus-end directed motors that transport cargo along the MTs from the cell periphery to the nucleus (Mandelkow and Mandelkow, 1995; King, 2000). Interference with dynein activity through over expression of dynamitin (dynactin complex disruptor) or through treatment of cells with sodium orthovanadate (an inhibitor of dynein activity) resulted in reduced KSHV genomic DNA in the nucleus of infected cells (Naranatt et al., 2005). These observations indicated significant roles of MTs and dyneins in the transportation of incoming KSHV particles toward the nucleus. The above functional roles exerted by MTs and dyneins are in lines with similar roles exerted by them in related herpesviruses such as HSV-1 (Douglas et al., 2004; Döhner et al., 2006; Diefenbach et al., 2008) and HCMV (Ogawa-Goto et al., 2003).

In HSV-1, inner tegument proteins, VP16, VP1-3, UL37, recruit dynein and dynactin mediating transportation of viral particles along the MTs (Luxton et al., 2005; Wolfstein et al., 2006). Both untegumented naked capsids and completely tegumented capsids of HSV failed to recruit the dynein motors, indicating a role of inner tegument proteins in recruiting cellular cytoskeletal elements (Wolfstein et al., 2006). This gives rise to an interesting premise that tegument proteins of KSHV could also exert a similar role in dynein-mediated transport of viral particles on MTs. To date, KSHV virion protein/s mediating transportation of incoming KSHV particles to the nucleus remains unidentified thus providing a very fertile ground for research.

The tegument protein ORF75 of MHV-4 (a murine gammaherpesvirus) has been hypothesized to exert a role in incoming viral particle transportation based on two experimental observations. The first was a significant reduction in the peri-nuclear capsid staining with majority of the particles scattered in the cytoplasm, during examination of ORF75- virus infected BHK-21 cells by immunofluorescence. The second observation was the defectiveness of ORF75- viral particles in establishing an infection subsequent to intranasal infection of mice. This was illustrated by a steady increase in the viral genome copy numbers in the lungs of wild-type virus infected mice, which was not noticed in the ORF75 $^{-}$virus infected animals. These observations suggest a role of ORF75 in associating the incoming MHV-4 viral particles to the host motor proteins (Gaspar et al., 2008). On similar lines, the ORF75 homolog in EBV, BNRF1, mediates the transportation of 
incoming viral particles from the endosomal compartments to the nucleus (Feederle et al., 2006).

\section{PERSPECTIVES ON THE ROLES OF KSHV TEGUMENT PROTEINS IN VIRAL ENTRY PATHWAYS}

As the outermost components of incoming KSHV particles, the tegument proteins have the potential to mediate viral particle transportation to the nucleus through interactions with the cellular cytoskeleton. In the absence of comprehensive studies on this aspect, there are certain issues which would need to be resolved. One is the identification of KSHV protein(s) participating in the transport of incoming viral particles through interactions with the cellular cytoskeleton elements. KSHV inner tegument components may be involved in interaction with dyneins and MTs, as the outer tegument components are released into the cytosol subsequent to entry.

Yet another interesting aspect would be identifying if any of the KSHV tegument proteins play a role in the induction of host cell signaling pathway proteins that regulate cellular cytoskeleton dynamics. In fact, KSHV cellular entry has been shown to induce Rho GTPases leading to acetylation of MTs, promoting MT reorganization and transportation of incoming viral particles to the nucleus (Sharma-Walia et al., 2004; Naranatt et al., 2005; Veettil et al., 2006; Raghu et al., 2007; reviewed in Chandran, 2010).

\section{REGULATORY ROLES EXERTED BY KSHV TEGUMENT PROTEINS \\ ROLES OF ORF45 IN EVASION OF IFN-MEDIATED ANTI-VIRAL RESPONSE} Primary KSHV infection gets initiated with the binding of viral glycoproteins to host cell surface receptors. This event elicits type I IFNs that constitute the first line of the innate anti-viral defense mechanism of host cell against the invading virus (reviewed in Sathish and Yuan, 2011). Induction of type I IFNs is influenced by a group of proteins, belonging to the family of IFN regulatory factors (IRFs). Among the nine different IRFs identified to date, IRFs 3 and 7 contribute significantly to the type I IFN induction (Honda et al., 2005a,b; Honda and Taniguchi, 2006; Hiscott, 2007). Subsequent to a viral infection, the toll-like receptors recognize viruses and through specific signaling pathways bring about the activation of IRFs. Activation of IRFs involves their phosphorylation and subsequent nuclear translocation, wherein they bind to the promoter regions of the type I IFN genes mediating their induction (Honda et al., 2005b). Recent observations have documented a greater potential of IRF-7 (as compared to IRF-3), in the induction of type I IFNs (Honda et al., 2005a,b). Type I IFNs thus induced, mediate the transcription of a diverse group of anti-viral effector proteins, the IFN stimulated genes (ISGs), which inhibit multiple stages of the viral life cycle (Goodbourn et al., 2000; Brierley and Fish, 2002; Sadler and Williams, 2008).

As type I IFNs are elicited immediately following a viral infection (Perry and Compton, 2006; Zhu et al., 2010), it is essential for incoming KSHV particles to effectively antagonize them for a successful establishment of a primary infection (reviewed in Sathish and Yuan, 2011). Noticeably reduced transcription of both type I IFN genes and their cognate receptors following primary KSHV infection of cultured cells has been documented (Perry and Compton, 2006). A similar observation witnessed subsequent to primary infection of cells with UV-irradiated KSHV virions, suggested an involvement of virion component proteins in disarming the type I IFN signaling initially triggered by viral glycoprotein attachment (Naranatt et al., 2004; Zhu et al., 2010).

Among the virion proteins, tegument proteins are the outermost components of incoming herpesvirus particles, exposed to the cellular milieu. Therefore the tegument proteins do have a potential to curtail the type I IFN responses. ORF45 was characterized as a tegument component mediating the type I IFN evasion in KSHV. Being a KSHV tegument protein, ORF45 is delivered to the cell cytosol at very early stages of KSHV infection (Zhu et al., 2010). ORF45 was shown to inhibit the activation of IRF-7, the master regulator of type I IFN responses, through inhibition of both its phosphorylation and nuclear translocation (Zhu et al., 2002; Sathish et al., 2011). The role of ORF45 in antagonizing type I interferon responses during primary infection was demonstrated using an ORF45-null recombinant virus. While cells infected with wild-type KSHV failed to induce anti-viral responses judged by their permissiveness to superinfection with vesicular stomatitis virus (VSV), infection of cells with an ORF45-null recombinant KSHV (BAC-stop45) resulted in increased transcription of type I IFN and downstream anti-viral effector genes that resisted VSV superinfection. In addition, a lentiviral mediated ectopic expression of ORF45 in human fibroblast cells diminished the host cell elicited type I IFN anti-viral responses (Zhu et al., 2010). Taken together, the inhibitory effect exerted by ORF45 on IRF-7 contributes to KSHV survival subsequent to a primary infection.

\section{ROLE OF ORF63 IN INHIBITION OF INFLAMMATION REACTION}

ORF63 has been identified as a KSHV virion tegument component (Russo et al., 1996; Zhu et al., 2005). A recent study revealed a vital role of this tegument protein in inhibiting the generation of the inflammasome. ORF63 shares amino acid sequence homology with NLRP1, specifically its nucleotide binding domain (NBD) and was found to interact with it (Gregory et al., 2011). NLRP1 is a protein of the nucleotide binding and oligomerization, leucine-rich repeat family (NLRs), which along with TLRs are placed under the broader group of pattern recognition receptors (Meylan et al., 2006). Activation pathways involving these NLRs culminate in the generation of inflammasomes, which are large multimeric protein complexes constituted by specific NLRs and procaspase-1 among others (Martinon et al., 2002). The inflammasomes induce the caspase- 1 mediated proteolytic processing of proinflammatory cytokines such as IL-1 $\beta$ and IL-18 (Stutz et al., 2009). Induction of these cytokines triggers pyroptosis, an inflammatory process involving caspase- 1 mediated death of infected cells.

The critical role of NLRP1 in combating KSHV was evidenced by the fact that knockdown of NLRP1 expression in BCBL-1 cells resulted in increased KSHV genomic DNA replication and infectious virion titers subsequent to lytic reactivation. Conversely, an siRNA-mediated knockdown of ORF63 resulted in reduced KSHV lytic gene expression and virion production along with significantly increased expression levels of IL-1 $\beta$ (Gregory et al., 2011). These observations suggested a role of ORF63 in mediating a potent reactivation of KSHV through inhibition of NLRP1 activity. ORF63 was found to inhibit both the oligomerization 
and the association of NLRP1 with active components of the inflammasome (Gregory et al., 2011).

\section{ORF64 ENCODES FOR A POTENT VIRAL DEUBIQUITINASE}

A KSHV large tegument protein encoded by ORF64 functions as a potent viral deubiquitinase (DUB) (González et al., 2009), an enzyme that removes ubiquitin (Ub) from either the cellular E3 ligase or the target protein thus abrogating the Ub-mediated regulation (Amerik and Hochstrasser, 2004). ORF64 homologues in related herpesviruses such as HSV-1 (Kattenhorn et al., 2005), HCMV (Wang et al., 2006), EBV (Sompallae et al., 2008), and MHV-68 (Gredmark et al., 2007) exhibit DUB activity. The DUB activity of KSHV ORF64 was localized to its first 205 amino acids in the N-terminal domain. Among the K48- and K63-linked Ub chains commonly targeted by DUBs, KSHV ORF64 has no distinct specificity to either of them and was capable of targeting both (González et al., 2009). This behavior is in sharp contrast to the DUBs of other herpesviruses, which had exclusive specificity for the K48-linked Ub chains alone (Amerik and Hochstrasser, 2004; Kattenhorn et al., 2005; Wang et al., 2006).

An siRNA-mediated knockdown of ORF64 resulted in decreased reactivation of KSHV from latency accompanied with decreased levels of viral lytic replication, suggesting a possible role of ORF64 in influencing the KSHV lytic cycle through its deubiquitination function (González et al., 2009). A recent study has documented a function of the KSHV ORF64 deubiquitinase in inhibiting the retinoic acid-inducible gene 1 (RIG-1) mediated type I IFN signaling (Inn et al., 2011). Though RIG-1 is known to be a cytosolic RNA sensor recognizing viral RNA, recent studies do indicate a role of this protein in recognition of DNA viruses like herpesviruses (Samanta et al., 2006, 2008; Rasmussen et al., 2009). A persistent presence of KSHV was noticed in RIG-1 deficient cells indicating an important role of this protein in influencing the outcome of primary KSHV infection. On these lines it was also observed that KSHV ORF64 inhibits the tripartite motif protein 25 (TRIM25) mediated ubiquitination of RIG-1 (Inn et al., 2011), a critical step essential for the initiation of the type I IFN signaling cascade (Gack et al., 2007).

In addition, ORF64, by virtue of its being a tegument component (Zhu et al., 2005), is delivered into cells during de novo infection, hence is efficiently poised to exert its DUB activity toward modifying the cellular environment. In this context, HSV1 DUB is known to be involved in multiple processes such as virion transportation along MTs, release of the viral nucleic acid into the host cell nucleus, tegumentation and viral egress pathways (Abaitua and O'Hare, 2008; Jovasevic et al., 2008; Shanda and Wilson, 2008). It remains to be clarified if KSHV ORF64 DUB also plays a similar role during de novo infection.

\section{ORF75 HOMOLOGUES TARGET COMPONENTS OF PROMYELOCYTIC LEUKEMIA NUCLEAR BODIES (PML NUCLEAR BODIES)}

MHV-68 tegument protein, ORF75c, has been shown to mediate the rapid degradation of promyelocytic leukemia protein (PML) nuclear bodies (NBs) through a proteasome-dependent mechanism (Gaspar et al., 2008; Ling et al., 2008). These PML NBs are dynamic nuclear organelles characterized by the presence of the PML and several other cellular proteins including Daxx, Sp100, and ATRX (Bernardi and Pandolfi, 2007; Everett and Chelbi-Alix,
2007). IFN treatment is known to directly trigger the transcription of several genes associated with PML NBs such as PML and Sp100, resulting in increased expression levels of these proteins and an increase in both the size and number of PML NBs (ChelbiAlix et al., 1995; Lavau et al., 1995; Grotzinger et al., 1996). These observations have suggested the involvement of PML NBs and its constituents in host anti-viral defense mechanisms (Everett and Chelbi-Alix, 2007).

The EBV homologue of MHV-68 ORF75c, BNRF1, known to influence establishment of viral latency (Feederle et al., 2006), has also been characterized as a PML NB interacting protein. BNRF1 specifically binds with Daxx, abrogating the association of ATRX (a Daxx-interacting partner) with Daxx, preventing the localization of this complex to the PML-NBs. In addition to interfering with the PML-mediated anti-viral defenses, this process also regulates the chromatin organization toward establishment of latent infection (Tsai et al., 2011).

Targeting PML NBs or their constituent proteins is not a unique property of gamma-herpesviruses. Similar to EBV BNRF1, the pp71 tegument protein of HCMV also interacts with Daxx. Unlike the BNRF1, pp71 induces the degradation of Daxx subsequent to displacement of ATRX (Lukashchuk et al., 2008). Furthermore, HSV-1 ICP0 mediates a proteasomal degradation of PML (Maul et al., 1993; Everett et al., 1998; Boutell et al., 2002). Yet only the de novo synthesized form is capable of this activity (Maul et al., 1993) unlike the tegument delivered ORF75c which exerts its effect immediately following viral infection. With the significance of PML-NBs and its constituents in influencing the outcome of a primary herpesviral infection, it is not surprising that multiple herpesviruses target PML-NBs or its constituent proteins through multiple mechanisms. It would be interesting to investigate if KSHV ORF75 also exerts a similar action on the PML-NBs.

\section{ROLES IN MANIPULATION OF CELLULAR SIGNALING}

Several tegument proteins of KSHV have been reported to regulate or interfere with cellular signal transduction.

(i) A study employing reverse transcription cell microarray (RTCM) technology identified ORF75 as a viral gene activating NF- $\kappa$ B. ORF75 was involved in the inactivation of IкB complexes, thereby promoting the nuclear translocation of NF- $\kappa B$ (Konrad et al., 2009; de Oliveira et al., 2010). Increased levels of NF- $\mathrm{B}$ are known to exert inhibitory effects on the activation of gamma-herpesvirus lytic promoters, lytic protein synthesis and virus replication (Brown et al., 2003). On the other hand, inhibition of NF- $\kappa \mathrm{B}$ activity in latently infected cells facilitates KSHV lytic protein synthesis reflective of viral reactivation (Grossmann and Ganem, 2008). These observations do suggest the involvement of NF- $\kappa \mathrm{B}$ in regulating the fine balance between the KSHV lytic and latent phases. In the context of a primary KSHV infection, the release of ORF75 tegument protein into cells subsequent to primary infection could activate NF- $\kappa$ B and help establish viral latency. Future experiments are needed to elucidate the role of ORF75 modulation of NF- $\kappa \mathrm{B}$ in KSHV viral latency.

(ii) ORF45 was shown to stimulate the kinase activities of two serine-threonine kinase proteins, RSK1 and RSK2 (Kuang 
et al., 2008). RSK1 and RSK2 belong to the family of 90-kDa ribosomal S6 kinases (RSKs) and are directly phosphorylated by mitogen-activated protein kinases (MAPKs) such as ERK1/ERK2. The activated RSKs in turn mediate the phosphorylation of many nuclear and cytoplasmic proteins influencing several biological processes such as gene expression, cell cycle and cell growth, cell survival and proliferation (Roux and Blenis, 2004; Hauge and Frodin, 2006). The RSKs are activated subsequent to both KSHV primary infection and lytic reactivation. A dramatic reduction in lytic gene expression and virion titers following lytic reactivation was seen in the cells exhibiting siRNA-mediated RSK knockdown, suggesting a role of these RSKs in pathways subsequent to KSHV lytic reactivation (Kuang et al., 2008).

Infection of cells with UV-irradiated KSHV resulted in activation of RSKs, indicating that a virion component protein participates in the activation (Sharma-Walia et al., 2005). ORF45-null mutant virus exhibited noticeably reduced activation of ERK/RSK in the cells infected in comparison to the levels with wild-type viral infection, indicating a role of ORF45 in the ERK/RSK activation (Kuang et al., 2008). A more recent study demonstrated that the binding of ORF45 to RSK also augments the association of
ERK to RSK, resulting in the generation of high-molecular weight complexes constituted by ORF45, RSK, and ERK. These complexes help to stabilize the otherwise transient interactions between active phosphorylated pERK and pRSK, also protecting them against cellular phosphatases (Kuang et al., 2009). Thus, the high-molecular weight complex-associated RSK and ERK are activated and sustained at levels sufficient to mediate their biological effects. Since the ERK/RSK MAPK signaling cascade promotes cell survival and proliferation, the ORF45-RSK-ERK complex may lead to prolonged cell survival contributing to KSHV viral pathogenesis.

\section{CONCLUDING REMARKS}

It is evident that tegument components of KSHV, which were previously less studied and understood, are slowly catching the attention of herpesvirologists. KSHV tegument components are known to influence several phases of the viral life cycle such as assembly and transportation of viral particles toward egress, transportation of incoming viral particles toward the nucleus, immune evasion processes and a multitude of other regulatory roles (an overview of the functional roles of KSHV tegument proteins is depicted in Table 1). In spite of this, a number of issues remain to be addressed. For example, it is unknown if KSHV tegument components influence the nuclear egress of capsids into cytosol

Table 1 | Functional roles of KSHV tegument proteins.

\begin{tabular}{|c|c|c|c|}
\hline Functional roles & ORF & Functional ability & Reference \\
\hline \multirow[t]{5}{*}{ In viral egress } & ORF64 & $\begin{array}{l}\text { Inner tegument proteins tethering to the capsid; Hub/scaffolding protein } \\
\text { mediating tegumentation and secondary envelopment processes }\end{array}$ & Rozen et al. (2008) \\
\hline & ORF45 & $\begin{array}{l}\text { Recruitment of KIF3A motor onto newly assembled viral tegumented } \\
\text { capsids for transportation along microtubules to trans-Golgi vesicles for } \\
\text { secondary envelopment }\end{array}$ & Sathish et al. (2009) \\
\hline & ORF52 & Contributes to tegumentation and secondary envelopment processes & Bortz et al. (2007) \\
\hline & ORF33 & Contributes to tegumentation and secondary envelopment processes & Guo et al. (2009) \\
\hline & To be identified & Possible role in nuclear egress of capsids & \\
\hline \multirow[t]{2}{*}{ In viral ingress } & To be identified & $\begin{array}{l}\text { Probable role in recruitment of dynein motors mediating transportation of } \\
\text { incoming viral particles along microtubules to the nucleus }\end{array}$ & Naranatt et al. (2005) \\
\hline & To be identified & $\begin{array}{l}\text { Probable role in induction and modulation of host cell signaling molecules } \\
\text { (e.g., RhoA) that promote acetylation and stabilization of microtubules and } \\
\text { change cell physical status }\end{array}$ & Chandran (2010) \\
\hline \multicolumn{4}{|l|}{ Regulatory roles } \\
\hline \multirow[t]{2}{*}{ Immune evasion } & ORF45 & $\begin{array}{l}\text { Inhibition of type I IFN-mediated innate anti-viral responses through } \\
\text { inhibition of IRF-7 activation }\end{array}$ & Zhu et al. (2010) \\
\hline & ORF63 & $\begin{array}{l}\text { Prevention of caspase- } 1 \text { activation and inhibition of induction of interleukins } \\
\mathrm{IL}-1 \beta \text { and IL-18 through inhibition of inflammasome formation }\end{array}$ & Gregory et al. (2011) \\
\hline \multirow[t]{4}{*}{ Other regulatory roles } & $\begin{array}{l}\text { To be identified } \\
\text { (ORF75 probably) }\end{array}$ & Inhibition of NF-кB activation helping to establish viral latency & Konrad et al. (2009) \\
\hline & ORF64 & $\begin{array}{l}\text { A possible role of its deubiquitinase activity in multiple processes including } \\
\text { virion transportation along microtubules, release of viral nucleic acid into } \\
\text { the host cell nucleus, tegumentation, and viral egress }\end{array}$ & González et al. (2009) \\
\hline & & $\begin{array}{l}\text { Inhibition of the retinoic acid-inducible gene } 1 \text { (RIG 1) mediated type IIFN } \\
\text { signaling }\end{array}$ & Inn et al. (2011) \\
\hline & ORF45 & $\begin{array}{l}\text { Generation of high-molecular complexes with RSK and ERK, activating and } \\
\text { sustaining their activities probably contributing to prolonged cell survival } \\
\text { and thus KSHV viral pathogenesis }\end{array}$ & Kuang et al. $(2008,2009)$ \\
\hline
\end{tabular}


during viral assembly. It would also be interesting to investigate if tegument proteins contribute to establishment of latency. Findings from these studies could serve as examples of the diverse functional capabilities of the tegument proteins.

Some cellular proteins have been found within the KSHV virions, presumably in the tegument layer (Zhu et al., 2005). Although the functions of these cellular proteins in KSHV virion have not been revealed, it is possible that some of these proteins are specifically recruited into virions to exert important roles in viral life cycle. Some of the cellular proteins identified in $\mathrm{KSHV}$ virions such as non-muscle $\beta$-actin, annexins, Hsp70, Hsp90, 14-3-3, and APOBEC3G have also been detected in other herpesviruses, other non-herpes DNA viruses and RNA viruses (Johannsen et al., 2004; del Rio et al., 2005; Chung et al., 2006;

\section{REFERENCES}

Abaitua, F., and O'Hare, P. (2008). Identification of a highly conserved, functional nuclear localization signal within the $\mathrm{N}$-terminal region of herpes simplex virus type 1 VP12 tegument protein. J. Virol. 82, 5234-5244.

Akula, S. M., Naranatt, P. P., Walia, N. S., Wang, F. Z., Fegley, B., and Chandran, B. (2003). Kaposi's sarcomaassociated herpesvirus (human herpesvirus 8) infection of human fibroblast cells occurs through endocytosis. J. Virol. 77, 7978-7990.

Akula, S. M., Naranatt, P. P., Wang, F. Z., and Chandran, B. (2001). Human herpesvirus envelope-associated glycoprotein B interacts with heparan sulfate-like moieties. Virology 284, 235-249.

Akula, S. M., Naranatt, P. P., Wang, F. Z., and Chandran, B. (2002). Integrin $\alpha 3 \beta 1(\mathrm{CD} 49 \mathrm{c} / 29)$ is a cellular receptor for Kaposi's sarcoma-associated herpesvirus (KSHV/HHV8) entry into target cells. Cell 108, 407-419.

Amerik, A. Y., and Hochstrasser, M. (2004). Mechanism and function of deubiquitinating enzymes. Biochim. Biophys. Acta 1695, 189-207.

Antman, K., and Chang, Y. (2000). Kaposi's sarcoma. N. Engl. J. Med. 342, 1027-1038.

Baghian, A., Luftig, M., Black, J. B., Meng, Y. X., Pau, C. P., Voss, T., Pellett, P. E., and Kousoulas, K. G. (2000). Glycoprotein B of human herpesvirus 8 is a component of the virion in a cleaved form composed of amino- and carboxylterminal fragments. Virology 269, 18-25.

Ballestas, M. E., Chatis, P. A., and Kaye, K. M. (1999). Efficient persistence of extrachromosomal KSHV DNA mediated by latencyassociated nuclear antigen. Science 284, 641-644.
Bechtel, J. T., Winant, R. C., and Ganem, D. (2005). Host and viral proteins in the virion of Kaposi's sarcomaassociated herpesvirus. J. Virol. 79, 4952-4964.

Benach, J., Wang, L., Chen, Y., Ho, C. K., Lee, S., Seetharaman, J., Xiao, R., Acton, T. B., Montelione, G. T., Deng, H., Sun. R., and Tong, L. (2007). Structural and functional studies of the abundant tegument protein ORF52 from murine gammaherpesvirus 68. J. Biol. Chem. 282, 31534-31541.

Bernardi, R., and Pandolfi, P. P. (2007). Structure, dynamics and functions of promyelocytic leukaemia nuclear bodies. Nat. Rev. Mol. Cell Biol. 8, 1006-1016.

Birkmann, A., Mahr, K., Ensser, A., Yaguboglu, S., Titgemeyer, F., Fleckenstein, B., and Neipel, F. (2001). Cell surface heparan sulfate is a receptor for human herpesvirus 8 and interacts with envelope glycoprotein K8.1. J. Virol. 75, 11583-11593.

Bortz, E., Wang, L., Jia, Q., Wu, T. T., Whitelegge, J. P., Deng, H., Zhou, Z. H., and Sun, R. (2007). Murine gammaherpesvirus 68 ORF52 encodes a tegument protein required for virion morphogenesis in the cytoplasm. J. Virol. 81, 10137-10150.

Bortz, E., Whitelegge, J. P., Jia, Q., Zhou, Z. H., Stewart, J. P., Wu, T.-T., and Sun, R. (2003). Identification of proteins associated with murine gammaherpesvirus 68 virions. J. Virol. 77, 13425-13432.

Boutell, C., Sadis, S., and Everett, R. D. (2002). Herpes simplex virus type 1 immediate-early protein ICP0 and is isolated RING finger domain act as ubiquitin E3 ligases in vitro. J. Virol. 76, 841-850.

Brierley, M. M., and Fish, E. N. (2002). Review: IFN-alpha/beta receptor interactions to biologic outcomes:

Loret et al., 2008; Kramer et al., 2011). Pharmacological inhibition of Hsp90 or its knockdown by siRNA has been shown to inhibit replication of several RNA viruses such as HCV and VSV (Connor et al., 2007; Nakagawa et al., 2007), indicating the significance of virus associated cellular proteins. Understanding functions of the cellular proteins in KSHV tegument and their interaction with viral tegument proteins or other virion proteins would lead to a better understanding of the multiple facets of the KSHV life cycle. To conclude, we expect to see a great increase in the number of studies addressing the biological functions of tegument components of KSHV, and of other herpesviruses. Future studies on these fascinating proteins should herald the onset of a new chapter in our ever evolving understanding of herpesvirus biology.

understanding the circuitry. J. Interferon Cytokine Res. 22, 835-845.

Brown, H. J., Song, M. J., Deng, H., Wu, T.-T., Cheng, G., and Sun, R. (2003). NF-k-B inhibits gammaherpesvirus lytic replication. J. Virol. 77, 8532-8540.

Cesarman, E., Chang, Y., Moore, P. S., Said, J. W., and Knowles, D. M. (1995a). Kaposi's sarcomaassociated herpesvirus-like DNA sequences in AIDS-related bodycavity-based lymphomas. N. Engl. J. Med. 332, 1186-1191.

Cesarman, E., Moore, P. S., Rao, P. H., Inghirami, G., Knowles, D. M., and Chang, Y. (1995b). In vitro establishment and characterization of two acquired immunodeficiency syndrome-related lymphoma cell lines (BC-1 and BC-2) containing Kaposi's sarcoma-associated herpesvirus-like (KSHV) DNA sequences. Blood 86, 2708-2714.

Cesarman, E., Mesri, E. A., and Gershengorn, M. C. (2000). Viral G proteincoupled receptor and Kaposi's sarcoma: a model of paracrine neoplasia? J. Exp. Med. 191, 417-422.

Chandran, B. (2010). Early events in Kaposi's sarcoma-associated herpesvirus infection of target cells. $J$. Virol. 84, 2188-2199.

Chang, Y., Cesarman, E., Pessin, M. S., Lee, F., Culpepper J., Knowles, D. M, and Moore, P. S. (1994). Identification of herpesvirus-like DNA sequences in AIDS associated Kaposi's sarcoma. Science 266, 1865-1869.

Chelbi-Alix, M. K., Pelicano, L., Quignon, F., Koken, M. H., Venturini, L., Stadler, M., Pavlovic, J., Degos, L., and de Thé, H. (1995). Induction of the PML protein by interferons in normal and APL cells. Leukemia 9, 2027-2033.

Chen, D., Jiang, H. H., Lee, M., Liu, F., and Zhou, Z. H. (1999). Three-dimensional visualization of tegument/capsid interactions in the intact human cytomegalovirus. Virology 260, 10-16.

Chuck, S., Grant, R. M., KatongoleMbidde, E., Conant, M., and Ganem, D. (1996). Frequent presence of a novel herpesvirus genome in lesions of human immunodeficiency virusnegative Kaposi's sarcoma. J. Infect. Dis. 173, 248-251.

Chung, C., Chen, C., Ho, M., Huang, C., Liao, C., and Chang, W. (2006). Vaccinia virus proteome: identification of proteins in vaccinia virus intracellular mature virion particles. J. Virol. $80,2127-2140$.

Connor, J. H., McKenzie, M. O., Parks, G. D., and Lyles, D. S. (2007). Antiviral activity and RNA polymerase degradation following Hsp90 inhibition in a range of negative strand viruses. Virology 362, 109-119.

Dai, W., Jia, Q., Bortz, E., Shah, S., Liu, J., Atanasov, I., Li, X., Taylor, K. A., Sun, R., and Zhou, Z. H. (2008). Unique structures in a tumor herpesvirus revealed by cryo-electron tomography and microscopy. J. Struct. Biol. 161, 428-438.

de Oliveira, D. E., Ballon, G., and Cesarman, E. (2010). NF-kappaB signaling modulation by EBV and KSHV. Trends Microbiol. 18, 248-257.

del Rio, T., DeCoste, C. J., and Enquist, L. W. (2005). Actin is a component of the compensation mechanism in pseudorabies virus virions lacking the major tegument protein VP22. J. Virol. 79, 8614-8619.

Dezube, B. J. (1996). Clinical presentation and natural history of AIDS - related Kaposi's sarcoma. Hematol. Oncol. Clin. North Am. 10, 1023-1029.

Diefenbach, R. J., Miranda-Saksena, M., Douglas, M. W., and Cunningham, A. L. (2008). Transport and egress of herpes simplex virus in neurons. Rev. Med. Virol. 18, 35-51. 
Döhner, K., Radtke, K., Schmidt, S., and Sodeik, B. (2006). Eclipse phase of herpes simplex virus type 1 infection: efficient dynein-mediated capsid transport without the small capsid protein VP26. J. Virol. 80, 8211-8224.

Douglas, M. W., Diefenbach R. J., Homa, F. L., Miranda-Saksena, M., Rixon, F. J., Vittone, V., Byth, K., and Cunningham, A. L. (2004). Herpes simplex virus type 1 capsid protein VP26 interacts with dynein light chains RP3 and Tctexl and plays a role in retrograde cellular transport. J. Biol. Chem. 279, 28522-28530.

Dupin, N., Grandadam, M., Calvez, V., Gorin, I., Aubin, J. T., Havard, S., Lamy, F., Leibowitch, M., Huraux, J. M., Escande, J. P., and Agut, H. (1995). Herpesvirus-like DNA sequences in patients with Mediterranean Kaposi's sarcoma. Lancet 345, 761-762.

Everett, R. D., and Chelbi-Alix, M. K. (2007). PML and PML nuclear bodies: implications in antiviral defence. Biochimie 89, 819-830.

Everett, R. D., Freemont, P., Saitoh, H., Dasso, M., Orr, A., Kathoria, M., and Parkinson, J. (1998). The disruption of ND10 during herpes simplex virus infection correlates with the Vmw110- and proteasomedependent loss of several PML isoforms. J. Virol. 72, 6581-6591.

Feederle, R., Neuhierl, B., Baldwin, G., Bannert, H., Hub, B., Mautner, J., Behrends, U., and Delecluse, H. J. (2006). Epstein-Barr virus BNRF1 protein allows efficient transfer from the endosomal compartment to the nucleus of primary B lymphocytes. J. Virol. 80, 9435-9443.

Gack, M. U., Shin, Y. C., Joo C.H., Urano, T., Liang, C., Sun, L., Takeuchi, O., Akira, S., Chen, Z., Inoue, S., and Jung, J. U. (2007). TRIM25 RING-finger E3 ubiquitin ligase is essential for RIG-Imediated antiviral activity. Nature 446, 916-920.

Ganem, D. (2007). "Kaposi's sarcomaassociated herpesvirus," in Fields Virology, 5th Edn, eds D. M. Knipe, P. M. Howley, D. E. Griffin, R. A. Lamb, M. A. Martin, B. Roizman, and S. E. Straus (Philadelphia, PA: Lippincott Williams \& Wilkins), 2875-2888.

Ganem, D. (2010). KSHV and the pathogenesis of Kaposi sarcoma: listening to human biology and medicine. J. Clin. Invest. 120, 939-949.

Gaspar, M., Gill, M. B., Lösing, J. B., May, J. S., and Stevenson, P. G. (2008). Multiple functions for ORF75c in murid herpesvirus-4 infection. PLoS
ONE 3, e2781. doi:10.1371/journal.pone.0002781

González, C. M., Wang, L., and Damania, B. (2009). Kaposi's sarcomaassociated herpesvirus encodes a viral deubiquitinase. J. Virol. 83, 10224-10233.

Goodbourn, S., Didcock, L., and Randall, R. E. (2000). Interferons: cell signalling, immune modulation, antiviral response and virus countermeasures. J. Gen. Virol. 81, 2341-2364.

Gredmark, S., Schlieker, C., Quesada, V., Spooner, E., and Ploegh, H. L. (2007). A functional ubiquitinspecific protease embedded in the large tegument protein (ORF64) of murine gammaherpesvirus 68 is active during the course of infection. J. Virol. 81, 10300-10309.

Gregory, S. M., Davis, B. K., West, J. A., Taxman, D. J., Matsuzawa, S., Reed, J. C., Ting, J. P., and Damania, B. (2011). Discovery of a viral NLR homolog that inhibits the inflammasome. Science 331, 330-334.

Grossmann, C., and Ganem, D. (2008). Effects of NFKB activation on KSHV latency and lytic reactivation are complex and context-dependent. Virology 375, 94-102.

Grotzinger, T., Jensen, K., and Will, H. (1996). The interferon (IFN)stimulated gene Sp100 promoter contains an IFN-gamma activation site and an imperfect IFNstimulated response element which mediate type I IFN inducibility. $J$. Biol. Chem. 271, 25253-25260.

Grundhoff, A., and Ganem, D. (2004). Inefficient establishment of KSHV latency suggests an additional role for continued lytic replication in Kaposi sarcoma pathogenesis. J. Clin. Invest. 113, 124-136.

Guo, H., Wang, L., Peng, L., Zhou, Z. H., and Deng, H. (2009). Open reading frame 33 of a gammaherpesvirus encodes a tegument protein essential for virion morphogenesis and egress. J. Virol. 83, 10582-10595.

Hahn, A., Birkmann, A., Wies, E., Dorer, D., Mahr, K., Stürzl, M., Titgemeyer, F., and Neipel, F. (2009). Kaposi's sarcoma-associated herpesvirus gH/gL: glycoprotein export and interaction with cellular receptors. J. Virol. 83, 396-407.

Hauge, C., and Frodin, M. (2006). RSK and MSK in MAP kinase signalling. J. Cell Sci. 119, 3021-3023.

Hirokawa, N. (2000). Stirring up development with the heterotrimeric kinesin KIF3. Traffic 1, 29-34.

Hiscott, J. (2007). Triggering the innate antiviral response through IRF-3 activation. J. Biol. Chem. 282, 15325-15329.

Honda, K., and Taniguchi, T. (2006). IRFs: master regulators of signaling by Toll-like receptors and cytosolic pattern-recognition receptors. Nat. Rev. Immunol. 6, 644-658.

Honda, K., Yanai, H., Negishi, H., Asagiri, M., Sato, M., Mizutani, T., Shimada, N., Ohba, Y., Takaoka, A., Yoshida, N., and Taniguchi, T. (2005a). IRF-7 is the master regulator of type-I interferon-dependent immune responses. Nature 434 772-777.

Honda, K., Hideyuki, Y., Takaoka, A., and Taniguchi, T. (2005b). Regulation of the type I IFN induction: a current view. Int. Immunol. 17, 1367-1378.

Inn, K. S., Lee, S. H., Rathbun, J. Y., Wong, L. Y., Toth, Z., Machida, K., Ou, J. H., and Jung, J. U. (2011). Inhibition of RIG-I-mediated signaling by Kaposi's sarcomaassociated herpesvirus-encoded deubiquitinase ORF64. J. Virol. 85, 10899-10904.

Jenner, R. G., and Boshoff, C. (2002). The molecular pathology of Kaposi's sarcoma-associated herpesvirus. Biochim. Biophys. Acta 1602, 1-22.

Johannsen, E., Luftig, M., Chase, M. R., Weicksel, S., Cahir-McFarland, E., Illanes, D., Sarracino, D., and Kieff, E. (2004). Proteins of purified Epstein-Barr virus. Proc. Natl. Acad. Sci. U.S.A. 101, 16286-16291.

Jovasevic, V., Liang, L., and Roizman, B. (2008). Proteolytic cleavage of VP1-2 is required for release of herpes simplex virus 1 DNA into the nucleus. J. Virol. 82, 3311-3319.

Kaleeba, J. A., and Berger, E. A. (2006). Kaposi's sarcoma-associated herpesvirus fusion-entry receptor: cystine transporter xCT. Science 311, 1921-1924.

Kattenhorn, L. M., Korbel, G. A., Kessler, B. M., Spooner, E., and Ploegh, H. L. (2005). A deubiquitinating enzyme encoded by HSV-1 belongs to a family of cysteine proteases that is conserved across the family Herpesviridae. Mol. Cell 19, 547-557.

King, S. M. (2000). The dynein microtubule motor. Biochim. Biophys. Acta 1496, 60-75.

Konrad, A., Wies, E., Thurau, M. Marquardt, G., Naschberger, E. Hentschel, S., Jochmann, R., Schulz, T. F., Erfle, H., Brors, B., Lausen, B. Neipel, F., and Stürzl, M. (2009). A systems biology approach to identify the combination effects of human herpesvirus 8 genes on NF-kappaB activation. J. Virol. 83, 2563-2574.
Koyano, S., Mar, E. C., Stamey, F. R., and Inoue, N. (2003). Glycoproteins M and $\mathrm{N}$ of human herpesvirus 8 form a complex and inhibit cell fusion. $J$ Gen. Virol. 84, 1485-1491.

Kramer, T., Greco, T. M., Enquist, L. W., and Cristea, I. M. (2011). Proteomic characterization of pseudorabies virus extracellular virions. J. Virol. 85, 6427-6441.

Kuang, E., Tang, Q., Maul, G. G., and Zhu, F. (2008). Activation of p90 ribosomal S6 kinase by ORF45 of Kaposi's sarcoma-associated herpesvirus and its role in viral lytic replication. J. Virol. 82, 1838-1850.

Kuang, E., Wu, F., and Zhu, F. (2009). Mechanism of sustained activation of ribosomal S6 kinase (RSK) and ERK by kaposi sarcoma-associated herpesvirus ORF45: multiprotein complexes retain active phosphorylated ERK AND RSK and protect them from dephosphorylation. J. Biol. Chem. 284, 13958-13968.

Lavau, C., Marchio, A., Fagioli, M., Jansen, J., Falini, B., Lebon, P., Grosveld, F., Pandolfi, P. P., Pelicci, P. G., and Dejean, A. (1995). The acute promyelocytic leukaemia-associated PML gene is induced by interferon. Oncogene 11, 871-876.

Ling, P. D., Tan, J., Sewatanon, J., and Peng, R. (2008). Murine gammaherpesvirus 68 open reading frame $75 \mathrm{c}$ tegument protein induces the degradation of PML and is essential for production of infectious virus. $J$. Virol. 82, 8000-8012.

Liu, Y., Cui, Z., Zhang, Z., Wei, H. Zhou, Y., Wang, M., and Zhang, X. E. (2009). The tegument protein UL94 of human cytomegalovirus as a binding partner for tegument protein pp28 identified by intracellular imaging. Virology 388, 68-77.

Loret, S., Guay, G., and Lippé, R. (2008). Comprehensive characterization of extracellular herpes simplex virus type 1 virions. J. Virol. 82, 8605-8618.

Lukashchuk, V., McFarlane, S., Everett, R. D., and Preston, C. M. (2008). Human cytomegalovirus protein pp71 displaces the chromatinassociated factor ATRX from nuclear domain 10 at early stages of infection. J. Virol. 82, 12543-12554.

Luxton, G. W., Haverlock, S., Coller, K. E., Antinone, S. E., Pincetic, A., and Smith, G. A. (2005). Targeting of herpesvirus capsid transport in axons is coupled to association with specific sets of tegument proteins. Proc. Natl. Acad. Sci. U.S.A. 102, 5832-5837.

Mandelkow, E., and Mandelkow, E. M. (1995). Microtubules and 
microtubule-associated proteins. Curr. Opin. Cell Biol. 7, 72-81.

Martin, D. F., Kuppermann, B. D., Wolitz, R. A., Palestine, A. G., Li, H. and Robinson, C. A. (1999). Oral ganciclovir for patients with cytomegalovirus retinitis treated with a ganciclovir implant. Roche Ganciclovir Study Group. N. Engl. J. Med. 340, 1063-1070.

Martinon, F., Burns, K., and Tschopp, J. (2002). The inflammasome: a molecular platform triggering activation of inflammatory caspases and processing of proIL- $\beta$. Mol. Cell 10, 417-426.

Maul, G. G., Guldner, H. H., and Spivack, J. G. (1993). Modification of discrete nuclear domains induced by herpes simplex virus type 1 immediate early gene 1 product (ICP0). J. Gen. Virol. 74, 2679-2690.

May, J. S., Coleman, H. M., Boname, J. M., and Stevenson, P. G. (2005a). Murine gammaherpesvirus-68 ORF28 encodes a non-essential virion glycoprotein. J. Gen. Virol. 86, 919-928.

May, J. S., Walker, J., Colaco, S., and Stevenson, P. G. (2005b). The murine gammaherpesvirus 68 ORF27 gene product contributes to intercellular viral spread. J. Virol. 79, 5059-5068.

McNabb, D., and Courtney, R. (1992). Characterization of the large tegument protein (ICP1/2) of herpes simplex virus type 1. Virology 190, 221-232.

Meckes, D. G. Jr., and Wills, J. W. (2007). Dynamic interactions of the UL16 tegument protein with the capsid of herpes simplex virus. J. Virol. 81, 13028-13036.

Mettenleiter, T. C. (2002). Herpesvirus assembly and egress. J. Virol. 76, 1537-1547.

Mettenleiter, T. C., Klupp, B. G., and Granzow, H. (2009). Herpesvirus assembly: an update. Virus Res. 143, 222-234.

Meylan, E., Tschopp, J., and Karin, M. (2006). Intracellular pattern recognition receptors in the host response. Nature 442, 39-44

Miller, G., Heston, L., Grogan, E., Gradoville, L., Rigsby, M., Sun, R., Shedd, D., Kushnaryov, V. M., Grossberg, S., and Chang, Y. (1997). Selective switch between latency and lytic replication of Kaposi's sarcoma herpesvirus and Epstein-Barr virus in dually infected body cavity lymphoma cells. J. Virol. 71, 314-324.

Moore, P. S., and Chang, Y. (1995). Detection of herpesvirus-like DNA sequences in Kaposi's sarcoma in patients with and without HIV infection. N. Engl. J. Med. 332, 1181-1185.

Moore, P. S., Gao, S. J., Dominguez, G., Cesarman, E., Lungu, O., Knowles, D. M., Garber, R., Pellett, P. E., McGeoch, D. J., and Chang, Y. (1996). Primary characterization of a herpesvirus agent associated with Kaposi's sarcoma. J. Virol. 70, 549-558.

Morfeldt, L., and Torssander, J. (1994). Long-term remission of Kaposi's sarcoma following foscarnet treatment in HIV-infected patients. Scand. J. Infect. Dis. 26, 749-752.

Nakagawa, S., Umehara, T., Matsuda, C., Kuge, S., Sudoh, M., and Kohara, M. (2007). Hsp90 inhibitors suppress HCV replication in replicon cells and humanized liver mice. Biochem. Biophys. Res. Commun. 353, 882-888.

Naranatt, P. P., Akula, S. M., and Chandran, B. (2002). Characterization of gamma2-human herpesvirus-8 glycoproteins $\mathrm{gH}$ and gL. Arch. Virol. 147, 1349-1370.

Naranatt, P. P., Krishnan, H. H., Smith, M. S., and Chandran, B. (2005). Kaposi's sarcoma-associated herpesvirus modulates microtubule dynamics via RhoA-GTP diaphanous 2 signaling and utilizes the dynein motors to deliver its DNA to the nucleus. J. Virol. 79, 1191-1206.

Naranatt, P. P., Krishnan, H. H., Svojanovsky, S. R., Bloomer, C., Mathur, S., and Chandran, B. (2004). Host gene induction and transcriptional reprogramming in Kaposi's sarcoma-associated herpesvirus (KSHV/HHV-8)-infected endothelial, fibroblast, and B cells: insights into modulation events early during infection. Cancer Res. $64,72-84$.

Nealon, K., Newcomb, W. W., Pray, T. R., Craik, C. S., Brown, J. C., and Kedes, D. H. (2001). Lytic replication of Kaposi's sarcoma-associated herpesvirus results in the formation of multiple capsid species: isolation and molecular characterization of $\mathrm{A}$, $\mathrm{B}$, and $\mathrm{C}$ capsids from a gammaherpesvirus. J. Virol. 75, 2866-2878.

Newcomb, W. W., and Brown, J. C. (2010). Structure and capsid association of the herpesvirus large tegument protein UL36. J. Virol. 84, 9408-9414.

Ogawa-Goto, K., Tanaka, K., Gibson, W., Moriishi, E., Miura, Y., Kurata, T., Irie, S., and Sata, T. (2003). Microtubule network facilitates nuclear targeting of human cytomegalovirus capsid. J. Virol. 77, 8541-8547.
Pellet, P. E., and Roizman, B. (2007). "The family Herpesviridae: a brief introduction," in Fields' Virology, 5th Edn, eds D. M. Knipe, P. Howley, D. E. Griffin, R. A. Lamb, M. A. Martin, B. Roizman, and S. E. Straus (New York, NY: Lippincott Williams \& Wilkins), 2479-2499.

Perry, S. T., and Compton, T. (2006). Kaposi's sarcoma-associated herpesvirus virions inhibit interferon responses induced by envelope glycoprotein gpK8.1. J. Virol. 80, 11105-11114.

Phillips, S. L., and Bresnahan, W. A. (2011). Identification of binary interactions between human cytomegalovirus virion proteins. $J$. Virol. 85, 440-447.

Raghu, H., Sharma-Walia, N., Valiya Veettil, M., Sadagopan, S., Caballero, A., Sivakumar, R., Varga, L., Bottero, V., and Chandran, B. (2007). Lipid rafts of primary endothelial cells are essential for Kaposi's sarcomaassociated herpesvirus/human herpesvirus 8-induced phosphatidylinositol 3-kinase and RhoA-GTPases critical for microtubule dynamics and nuclear delivery of viral DNA but dispensable for binding and entry. J. Virol. 81, 7941-7959.

Raghu, H., Sharma-Walia, N., Valiya Veettil, M., Sadagopan, S., and Chandran, B. (2009). Kaposi's sarcoma associated herpesvirus utilizes an actin polymerization-dependent macropinocytic pathway to enter human dermal microvascular endothelial and human umbilical vein endothelial cells. J. Virol. 83 , 4895-4911.

Rasmussen, S. B., Jensen, S. B., Nielsen, C., Quartin, E., Kato, H., Chen, Z. J., Silverman, R. H., Akira, S., and Paludan, S. R. (2009). Herpes simplex virus infection is sensed by both Toll-like receptors and retinoic acidinducible gene-like receptors, which synergize to induce type I interferon production. J. Gen. Virol. 90, 74-78.

Renne, R., Zhong, W., Herndier, B., McGrath, M., Abbey, N., Kedes, D., and Ganem, D. (1996). Lytic growth of Kaposi's sarcoma-associated herpesvirus (human herpesvirus 8 ) in culture. Nat. Med. 2, 342-346.

Roux, P. P., and Blenis, J. (2004). ERK and p38 MAPK-activated protein kinases: a family of protein kinases with diverse biological functions. Microbiol. Mol. Biol. Rev. 68 320-344.

Rozen, R., Sathish, N., Li, Y., and Yuan, Y. (2008). Virion-wide protein interactions of Kaposi's sarcomaassociated herpesvirus. J. Virol. 82, 4742-4750.
Russo, J. J., Bohenzky, R. A., Chien, M. C., Chen, J., Yan, M., Maddalena, D., Parry, J. P., Peruzzi, D., Edelman, I. S., Chang, Y., and Moore, P. S. (1996). Nucleotide sequence of the Kaposi sarcoma-associated herpesvirus (HHV8). Proc. Natl. Acad. Sci. USA 93, 14862-14867.

Sadler, A. J., and Williams, B. R. G. (2008). Interferon-inducible antiviral effectors. Nat. Rev. Immunol. 8, 559-568.

Samanta, M., Iwakiri, D., Kanda, T. Imaizumi, T., and Takada, K. (2006). EB virus-encoded RNAs are recognized by RIG-I and activate signaling to induce type I IFN. EMBO J. 25 , 4207-4214.

Samanta, M., Iwakiri, D., and Takada, K. (2008). Epstein-Barr virus-encoded small RNA induces IL-10 through RIG-I-mediated IRF-3 signaling. Oncogene 27, 4150-4160.

Sarid, R., Flore, O., Bohenzky, R. A., Chang, Y., and Moore, P. S. (1998). Transcription mapping of the Kaposi's sarcoma-associated herpesvirus (human herpesvirus 8) genome in a body cavity-based lymphoma cell line (BC-1). J. Virol. 72, 1005-1012.

Sathish, N., and Yuan, Y. (2010). Functional characterization of Kaposi's sarcoma-associated herpesvirus small capsid protein by bacterial artificial chromosome-based mutagenesis. Virology 407, 306-318.

Sathish, N., and Yuan, Y. (2011). Evasion and subversion of interferonmediated antiviral immunity by Kaposi's sarcoma-associated herpesvirus: an overview. J. Virol. 85, 10934-10944.

Sathish, N., Zhu, F. X., Golub, E. E., Liang, Q., and Yuan, Y. (2011) Mechanisms of autoinhibition of IRF-7 and a probable model for inactivation of IRF-7 by Kaposi's sarcoma-associated herpesvirus protein ORF45. J. Biol. Chem. 286, 746-756.

Sathish, N., Zhu, F. X., and Yuan, Y. (2009). Kaposi's sarcoma-associated herpesvirus ORF45 interacts with kinesin-2 transporting viral capsidtegument complexes along microtubules. PLoS Pathog. 5, e1000332. doi:10.1371/journal.ppat.1000332

Schalling, M., Ekman, M., Kaaya, E. E., Linde, A., and Biberfeld, P. (1995). A role for a new herpes virus (KSHV) in different forms of Kaposi's sarcoma. Nat. Med. 1, 707-708.

Shanda, S. K., and Wilson, D. W. (2008), UL36p is required for efficient transport of membrane-associated herpes simplex virus type 1 along microtubules. J. Virol. 82, 7388-7394. 
Sharma-Walia, N., Krishnan, H. H., Naranatt, P. P., Zeng, L., Smith, M. S., and Chandran, B. (2005). ERK1/2 and MEK1/2 induced by Kaposi's sarcoma associated herpesvirus (human herpesvirus 8) early during infection of target cells are essential for expression of viral genes and for establishment of infection. J. Virol. 79, 10308-10329.

Sharma-Walia, N., Naranatt, P. P., Krishnan, H. H., Zeng, L., and Chandran, B. (2004). Kaposi's sarcomaassociated herpesvirus/human herpesvirus 8 envelope glycoprotein $\mathrm{gB}$ induces the integrin-dependent focal adhesion kinase-Srcphosphatidylinositol 3-kinase rho GTPase signal pathways and cytoskeletal rearrangements. J. Virol. 78, 4207-4223.

Sompallae, R., Gastaldello, S., Hildebrand, S., Zinin, N., Hassink, G., Lindsten, K., Haas, J., Persson, B., and Masucci, M. G. (2008). EpsteinBarr virus encodes three bona fide ubiquitin-specific proteases. J. Virol. 82, 10477-10486.

Soulier, J., Grollet, L., Okshendler, E., Cacoub, P., Cazals-Hatem, D., Babinet, P., d'Agay, M. F., Clauvel, J.-P., Raphael, M., Degos, L., and Sigaux, F. (1995). Kaposi's sarcoma-associated herpesvirus-like DNA sequences in multicentric Castleman's disease. Blood 86, 1276-1280.

Stutz, A., Golenbock, D. T., and Latz, E. (2009). Inflammasomes: too big to miss. J. Clin. Invest. 119, 3502-3511.

Sun, R., Lin, S. F., Staskus, K., Gradoville, L., Grogan, E., Hasse, A., and Miller, G. (1999). Kinetics of Kaposi's sarcoma-associated herpesvirus gene expression. J. Virol. 73, 2232-2242.
Tsai, K., Thikmyanova, N., Wojcechowskyj, J. A., Delecluse, H. J., and Lieberman, P. M. (2011). EBV tegument protein BNRF1 disrupts DAXX-ATRX to activate viral early gene transcription. PLoS Pathog. 7, e1002376. doi:10.1371/journal.ppat.1002376

Veettil, M. V., Sadagopan, S., SharmaWalia, N., Wang, F.-Z., Raghu, H., Varga, L., and Chandran, B. (2008). Kaposi's sarcoma-associated herpesvirus forms a multimolecular complex of integrins $(\alpha \mathrm{v} \beta 5$, $\alpha v \beta 3$, and $\alpha 3 \beta 1$ ) and CD98-xCT during infection of human dermal microvascular endothelial cells, and CD98-xCT is essential for the postentry stage of infection. J. Virol. 82, 12126-12144.

Veettil, M. V., Sharma-Walia, N., Sadagopan, S., Raghu, H., Sivakumar, R., Naranatt, P. P., and Chandran, B. (2006). RhoA-GTPase facilitates entry of Kaposi's sarcomaassociated herpesvirus into adherent target cells in a Src-dependent manner. J. Virol. 80, 11432-11446.

Vittone, V., Diefenbach, E., Triffett, D., Douglas, M. W., Cunningham, A. L., and Diefenbach, R. J. (2005). Determination of interactions between tegument proteins of herpes simplex virus type 1. J. Virol. 79, 9566-9571.

Wang, F. Z., Akula, S. M., Pramod, N. O., Zeng, L., and Chandran, B. (2001). Human herpesvirus 8 envelope glycoprotein K8.1 interaction with the target cells involves heparan sulfate. J. Virol. 75, 7517-7527.

Wang, J., Loveland, A. N., Kattenhorn, L. M., Ploegh, H. L., and Gibson, W. (2006). High-molecularweight protein (pUL48) of human cytomegalovirus is a competent deubiquitinating protease: mutant viruses altered in its active-site cysteine or histidine are viable. J. Virol. 80, 6003-6012.

Wolfstein, A., Nagel, C. H., Radtke, K. Döhner, K., Allan, V. J., and Sodeik, B. (2006). The inner tegument promotes herpes simplex virus capsid motility along microtubules in vitro. Traffic 7, 227-237.

Yamazaki, H., Nakata, T., Okada, Y., and Hirokawa, N. (1995). KIF3A/B a heterodimeric kinesin superfamily protein that works as a microtubule plus end-directed motor for membrane organelle transport. J. Cell Biol. 130, 1387-1399.

Zhong, W., Wang, H., Herndier, B. and Ganem, D. (1996). Restricted expression of Kaposi sarcomaassociated herpesvirus (human herpesvirus 8) genes in Kaposi sarcoma. Proc. Natl. Acad. Sci. U.S.A. 93, 6641-6646.

Zhou, Z., Chen, D., Jakana, J., Rixon, F. J., and Chiu, W. (1999). Visualization of tegument-capsid interactions and DNA in intact herpes simplex virus type 1 virions. J. Virol. 73 , 3210-3218.

Zhu, F. X., Chong, J. M., Wu, L. and Yuan, Y. (2005). Virion proteins of Kaposi's sarcomaassociated herpesvirus. J. Virol. 79, 800-811.

Zhu, F. X., King, S. M., Smith, E. J., Levy, D. E., and Yuan, Y. (2002). A Kaposi's sarcoma-associated herpesviral protein inhibits virus-mediated induction of type I interferon by blocking IRF-7 phosphorylation and nuclear accumulation. Proc. Natl. Acad. Sci. U.S.A. 99, 5573-5578.

Zhu, F. X., Li, X., Zhou, F., Gao, S. J. and Yuan, Y. (2006). Functional characterization of Kaposi's sarcoma-associated herpesvirus ORF45 by bacterial artificial chromosome-based mutagenesis. J. Virol. 80, 12187-12196.

Zhu, F. X., Sathish, N., and Yuan, Y. (2010). Antagonism of host antiviral responses by Kaposi's sarcoma-associated herpesvirus tegument protein ORF45. PLoS ONE 5, e10573. doi:10.1371/ journal.pone.0010573

Zhu, F. X., and Yuan, Y. (2003). The ORF45 protein of Kaposi's sarcomaassociated herpesvirus is associated with purified virion. J. Virol. 77, 4221-4230.

Conflict of Interest Statement: The authors declare that the research was conducted in the absence of any commercial or financial relationships that could be construed as a potential conflict of interest.

Received: 25 November 2011; paper pending published: 26 December 2011; accepted: 28 February 2012; published online: 15 March 2012.

Citation: Sathish $N$, Wang $X$ and Yuan $Y$ (2012) Tegument proteins of Kaposi's sarcoma-associated herpesvirus and related gammaherpesviruses. Front. Microbio. 3:98. doi: 10.3389/fmicb.2012.00098

This article was submitted to Frontier in Virology, a specialty of Frontiers in Microbiology.

Copyright (c) 2012 Sathish, Wang and Yuan. This is an open-access article distributed under the terms of the Creative Commons Attribution Non Commercial License, which permits noncommercial use, distribution, and reproduction in other forums, provided the original authors and source are credited. 